\title{
Sinhogarismo inmigrante. Un caso de investigación-acción universitaria en el contexto de la recogida de aceituna en úbeda
}

\author{
Inmigrant homelessness. A case of university action-research in the \\ context of the olive harvest in Úbeda
}

\author{
Vicente Manzano-Arrondo, ${ }^{*}$ Beatriz Pedrosa Vico** y José Luis Soto Soto***
}

Fecha de recepción: 30-04-2017 - Fecha de aceptación: 16-09-2017

Hábitat y Sociedad (ISSN 2173-125X), n. ${ }^{\circ}$ 10, noviembre de 2017, pp. 223-244.

http://dx.doi.org/10.12795/HabitatySociedad.2017.i10.13

\begin{abstract}
When immigration results in homelessness, a phenomenon of deep social exclusion is created, with effects in individual, relational and structural scales. One of the contexts in which immigrant homelessness is observed is the agricultural one, in the annual campaigns where labor of temporary workers is required. This document addresses a research-action experience involving immigrants, local people and university, around the harvest of oil in Úbeda, municipality of the province of Jaén, in Spain. The results of several focus groups are shown, accomplished with immigrants, local population, teachers, students and administration and services staff of a university center. The results reinforce the need for urgent and complex intervention, not only describing a situation of profound structural helplessness, but also identifying several agents involved in the phenomenon, all of them inserted in global processes with local repercussions. In the midst of all this, the university must play a fundamental role, based on its status as an institution that generates relevant knowledge.
\end{abstract}

\section{Key words}

Inmigration, Homelessness, Unit of committed action, Action-research, Rol of university

\section{Resumen}

Cuando la inmigración deriva en sinhogarismo se crea un fenómeno de profunda exclusión social que afecta a escala individual, relacional y estructural. Uno de los contextos en los que se observa el sinhogarismo inmigrante es el agrícola, en las campañas anuales donde se requiere mano de obra de temporeros. Este documento aborda una experiencia de investigación-acción que implica a inmigrantes, población autóctona y universidad, en torno a la recogida de la aceituna en Úbeda, municipio de la provincia de Jaén, en España. Se muestran los resultados de varios grupos focales, realizados con inmigrantes, población local, profesorado, estudiantes y personal de administración y servicios de un centro universitario. Los resultados refuerzan la necesidad de una intervención urgente y compleja, pues no solo se describe una situación de profundo desamparo estructural, sino que también se identifican varios agentes implicados en el fenómeno, todos ellos insertos en procesos globales con repercusiones locales. En medio de todo ello, la universidad debe jugar un papel fundamental, basado en su condición de institución que genera conocimiento relevante.

\section{Pallabras clave}

Inmigración; Sinhogarismo; Unidad de acción comprometida; Investigación-acción; Papel de la universidad

\footnotetext{
* Departamento de Psicología Experimental. Universidad de Sevilla. c/ Camilo José s/n, 41005, Sevilla. C.e.: vmanzano@us.es. ** C.e.: bpedrosa@fundacionsafa.es.

*** Centro Universitario Sagrada Familia. Universidad de Jaén. Av. Cristo Rey, 17, 23400, Úbeda. C.e.: jlsoto@fundacionsafa.es.
} 
"Siempre ha sido más fácil y barato, perseguir a los pobres que luchar contra la pobreza" (Cabrera, 2009, p. 4).

\section{Introducción}

La realidad migratoria es una parte constitutiva de la cotidianidad planetaria. Desde una perspectiva no conflictiva, las migraciones cubren una función social y biológica fundamental, pues posibilitan satisfacer la necesidad de enriquecimiento mutuo entre culturas y bagajes hereditarios; mientras que el sedentarismo protege el acervo cultural zonal. Desde esa perspectiva, el motivo de las migraciones debería asentarse únicamente en el placer de conocer y experimentar. $\mathrm{Al}$ mismo tiempo, los individuos migrantes deberían ser recibidos desde la oportunidad del enriquecimiento, al menos cultural, que, a su vez, facilita la conciencia de lo propio mediante las similitudes y los contrastes, como ocurre en todo proceso de construcción identitaria (Saavedra, 2007).

La cotidianidad, no obstante, descubre una realidad muy diferente. La intensificación en la globalización economizadora, que parte de los años ochenta del siglo $\mathrm{xx}$, ha provocado mayores flujos migratorios, a la vez que los ha obstaculizado (Estefanía, 2001). Como resultado, las migraciones obedecen mayoritariamente a la lógica de la huida frente a situaciones locales de pauperización política, económica, social o medioambiental (Hildegard, 2012). En buena medida, los individuos emigran porque las sociedades de origen no permiten garantizar la supervivencia o hacerlo de manera suficiente o digna. En el lado de la acogida, el recibimiento se encuentra frecuentemente instalado en la instrumentalización del inmigrante, en su abandono o desamparo, y en el temor de que su presencia haga peligrar logros locales inestables. Por ello, la inmigración hoy es sinónimo de desequilibrio o desigualdad (Camps, 2000). Lora-Tamayo (1993) lista los problemas que justifican finalmente las altas cuotas de exclusión inmigrante, que podríamos sintetizar en (1) desamparo jurídico que deriva en (2) la participación dentro de la economía sumergida y (3) vulnerabilidad ante las redes clandestinas y mafiosas que obtienen beneficios de la ilegalidad; (4) fuerte presión económica de las familias de origen que frecuentemente han gastado todos sus ahorros en favorecer la salida de uno de sus miembros; (5) desconocimiento del idioma, las costumbres y los códigos de vida de la población receptora, que reacciona con (6) racismo y trato discriminatorio, en parte justificados por (7) desconfianza, a su vez fruto del bajo nivel de estudios y de preparación de quienes ven llegar o que reciben noticias sobre la llegada de inmigrantes; (8) hábitos de la cultura de origen que pueden facilitar la segregación; y (9) serias dificultades para acceder a una vivienda digna. Este último elemento afecta a toda la población, pero se agrava para inmigrantes, en parte debido a quienes se aprovechan de su situación vulnerable. En definitiva, esta acumulación de factores, que comienzan en el país de origen y se agravan durante el camino, terminan eclosionando en una auténtica bolsa de exclusión social en el país receptor, que frecuentemente reacciona con rechazo y discriminación proporcionales al grado de vulnerabilidad migrante (Hildegard, 2012).

$\mathrm{Al}$ hilo de todo ello, los problemas que sufre la migración suelen sumarse a los problemas derivados del hábitat marginal. Habitualmente, los trabajos que versan sobre este asunto se realizan en torno a las zonas urbanísticas pauperizadas. El excelente trabajo de Torres (2011) se 
sitúa en este marco y permite establecer una síntesis de características comunes. Así, de sus aportaciones pueden acotarse problemas de hábitat que, en términos físicos, muestran (1) viviendas con insuficientes condiciones internas de habitabilidad, (2) en edificios que acumulan síntomas de abandono, (3) insertos en urbanizaciones diseñadas para apilar personas, (4) con dificultades de conexión e incluso posiciones urbanísticas conflictivas respecto al resto de la ciudad. En términos psicosociales, sus habitantes sufren problemas de (5) inserción laboral y (6) estigmatización social. Finalmente, cuando las autoridades políticas ponen en marcha programas de intervención, habitualmente (7) parten de una mirada excesivamente parcial del problema, (8) con actuaciones cortoplacistas y (9) con efectos que se circunscriben con frecuencia a desplazar el problema, o que incluso lo agravan, aunque hayan supuesto una fuerte inversión económica y mediática.

Los problemas de hábitat que afectan a la población marginal autóctona no solo se observan también en la inmigrante, sino que se agravan en este caso, constituyendo un síndrome que podría denominarse de sinhogarismo inmigrante, fenómeno harto frecuente en las sociedades de acogida (Checa y Arjona, 2006). Ambos fenómenos terminan dando forma a unas condiciones de vida altamente injustas, que llevan a las personas a aceptar situaciones intolerables en otras circunstancias. Así, por ejemplo, según las últimas cifras de población disponibles, ${ }^{1}$ España cuenta con 46,5 millones de habitantes a 1 de julio de 2016, de los que un $9,5 \%$ son extranjeros. Sin embargo, a pesar de que el amplio grueso de la población española es autóctono, son extranjeras el 45,8\% de las personas que carecen de hogar, ${ }^{2}$ en su mayoría africanas $(56,6 \%)$.

Este documento se sitúa en esa confluencia de procesos de exclusión. Aborda la realidad de la inmigración que combina la precariedad sociolaboral con la de hábitat, ambas plenamente instaladas en funcionamientos sistémicos injustos. La población a que se refiere este documento se ubica en las campañas de la aceituna en el municipio de Úbeda, por lo que apunta a un colectivo de inmigrantes temporeros básicamente de interior, es decir, que transita de unas zonas a otras para ofrecer su fuerza de trabajo en campañas agrícolas acotadas en épocas precisas del año. El objetivo de la experiencia no es solo describir y comprender qué ocurre en torno a los temporeros inmigrantes que de noviembre a febrero acuden a la provincia de Jaén para la campaña de recogida de la aceituna. La principal motivación es diseñar instancias de solución. Se trata de una experiencia de investigación-acción participativa (IAP) que implica a todos los agentes que participan directa e indirectamente en la situación. No obstante, este documento describe específicamente una porción de la experiencia con significado suficiente y que afecta a inmigrantes, población autóctona y a miembros de dos universidades andaluzas.

Con este objetivo, el primer apartado de contenido plantea el concepto de vulnerabilidad migrante de hábitat, como punto de partida que inspira la IAP. El siguiente describe el diseño y trabajo de campo de la experiencia. El tercero aborda los resultados específicos de los cuatro grupos focales realizados. El epígrafe que le sigue interpreta la realidad local generando algunas preguntas fundamentales que atañen a los procesos globales. Finalmente, la discusión que cierra el documento organiza una visión de conjunto y la identificación de algunos retos abiertos.
1 http://www.ine.es/prensa/np1010. pdf.

2 http://www.ine.es/prensa/np761.pdf. 


\section{Vulnerabilidad migrante de hábitat}

El concepto vulnerabilidad ha sido abordado desde disciplinas muy dispares. Por lo general, se encuentra asociado a peligros de la naturaleza o socioeconómicos, mediante una notable diversidad de perspectivas que dificulta dar forma a una definición universal para el término (García del Castillo, 2015). Sin embargo, es posible acotar algunos elementos comunes (Ruiz, 2012; Villagrán, 2006), tales como: (1) vulnerable es la persona o el grupo; (2) lo es porque se encuentra ante la posibilidad real de recibir un daño; (3) respecto a lo que carece de suficientes recursos de afrontamiento como para garantizar que superará bien la eclosión de ese daño. Se trata de una cuestión de grado, de tal forma que lo acertado no es pensar en términos de existencia o no de vulnerabilidad, sino de una medida más o menos pronunciada de la misma.

La fuente de la vulnerabilidad no reside en quien la padece, sino en su relación con el medio. Así, una misma persona varía su grado de vulnerabilidad al cambiar de contexto, del mismo modo que bajo un mismo contexto, se manifiestan grados variables de vulnerabilidad. Hollomotz (2012) destaca este origen relacional y alerta que las expresiones del tipo "grupo vulnerable" desplazan la atención desde la relación hacia la víctima. De esta forma, las energías se concentran en paliar los efectos a nivel de la persona, desatendiendo la intervención en el sistema cuyo funcionamiento justifica el daño. No obstante, a juicio de los autores, esta alerta resulta tan acertada como difícil de solucionar en la práctica. Indicar, por ejemplo, que lo vulnerable es la relación, deja también desprotegida a la víctima, pues no sugiere atenderla al menos desde la óptica de una ética del cuidado. Una posibilidad es incluir la causa en la definición del constructo, de tal forma que resulte claro quién emite y quién recibe. De este modo, vulnerable es el individuo o el grupo expuesto a una alta probabilidad de recibir daño estructural, sin que existan garantías contextuales ni recursos individuales o relacionales suficientes como para prevenir el daño o revertir sus efectos.

En los estudios sobre el fenómeno migratorio y su análisis desde una perspectiva de justicia y bienestar, se incide en la importancia de los tres niveles mencionados: individual, relacional y contextual o estructural. Así, por ejemplo, Sánchez y Tezanos (2004) destacan que el sinhogarismo inmigrante ha de ser entendido "más allá de la exclusión residencial y centrarse en el plano convivencial/relacional/familiar, personal, asistencial y cultural” (ob. cit., p. 46). García-Ramírez, Mata, Paloma y Hernández-Plaza (2011) definen las características que deberían observarse en tales dimensiones para reconocer bienestar y justicia: (1) a nivel individual, el desarrollo de pensamiento crítico, la auto-determinación y la capacidad de control; (2) a nivel relacional, la existencia de una red de contactos protectora que suministra apoyo y sentido de comunidad; y, (3) a nivel estructural, la práctica de servicios multiculturales, de condiciones laborales justas y de posibilidades efectivas para la promoción de cambio social.

La realidad reportada por los estudios sobre las situaciones habituales en las que se desenvuelve la cotidianidad inmigrante es muy diferente. A nivel estructural, frecuentemente estas personas "ocupan los empleos más precarios, transitorios y peligrosos" (Guillén, Lucas, Pérez y Arias, 2001). Los mismos autores describen la respuesta de las administraciones públicas españolas en términos de "reacción por sorpresa", improvisando acciones y servicios que no alcanzan la cota de 
garantía estructural. El mencionado trabajo de Checa y Arjona (2006) considera que tres de cada cuatro inmigrantes se alojan en una vivienda no digna. Y, por su parte, Sánchez y Tezanos (2004) remarcan que la potente vulnerabilidad que se sufre en la sociedad de acogida se asienta en parte en la que ya sufrían estas personas en la sociedad de origen, insertas en un proceso continuo de pauperización.

La vulnerabilidad no tiene por qué generarse en torno a la vivienda, pero tiene en ella un componente fundamental, de tal forma que Lora-Tamayo (1993) aconseja comenzar a solucionar el acceso a una vivienda digna como piedra angular para acometer el resto de la solución. No contar con un alojamiento mínimo en el que dormir, asearse, guardar las pocas pertenencias y sentir seguridad, menoscaba otras fortalezas individuales y relacionales en la población migrante. El trabajo de García-Ramírez et al. (2011) describe este efecto en términos de tendencia a la sumisión, miedo, sentimientos de inferioridad, interiorización de la opresión y alta tolerancia a la discriminación. Los problemas de hábitat favorecen, asimismo, el deterioro de las relaciones interpersonales que, al sumarse al resto de los efectos, favorecen el desarraigo, la indigencia social y aumentan la respuesta de rechazo y discriminación por parte de la población autóctona, cerrando un ciclo de exclusión crónica (Hildegard, 2012).

\section{Descripción de la situación en úbeda}

Si bien los datos analizados en este documento han sido recogidos específicamente en el municipio de Úbeda, es importante señalar que el nivel municipal se muestra insuficiente para comprender los aspectos relacionados con la inmigración temporera. Los terrenos de cultivo se encuentran en términos municipales concretos, pero reciben mano de obra que se alberga, come o transita por zonas que no obedecen necesariamente a la unidad municipal, de tal forma que los servicios institucionales y el tránsito de mano de obra son asuntos que atañen a zonas mucho más amplias. En este contexto, además, es imposible conocer con precisión el número de personas extranjeras sin cobertura estructural que aspiran a encontrar un trabajo en la recogida de la aceituna, dado que no solo se trata de una población en tránsito, sino, además, en buena medida sin dejar registro estadístico. Por todo ello, los datos cuantitativos deben ser observados con mucha cautela y considerados únicamente como aproximaciones.

El estudio realizado por Gordo, Felicidades y Menor (2013) plantea una visión general para ubicar los problemas de hábitat en torno a la migración temporera que ronda la recogida de la aceituna en la provincia de Jaén, donde se sitúa Úbeda. Según estos autores, la cuarta parte de la superficie mundial dedicada al olivar se ubica en España, que a su vez es responsable de un tercio de la producción mundial de aceituna. Ocupa el primer puesto en ambas dimensiones, seguido por otros países mediterráneos. Casi el $40 \%$ de la producción estatal se genera en la provincia de Jaén, acaparando algo más del $90 \%$ de su superficie de cultivo. Esta intensa actividad productiva genera importantes necesidades de mano de obra, especialmente temporera y ceñida a los meses de noviembre a febrero, generando en torno a nueve millones de jornales en una campaña media. Buena parte de esta actividad está realizada por extranjeros que provienen de otras provincias españolas, en medio de itinerarios temporeros agrícolas. Esta circunstancia ha ge- 
3 Datos suministrados por la entidad específicamente para la redacción de este trabajo, tanto por parte de Cáritas como del Área de Servicios Sociales del Ayuntamiento de Úbeda. nerado la necesidad, normativamente regulada, de habilitar albergues y de obligar legalmente a los empleadores a facilitar alojamiento. Esta cobertura es efectiva cuando se trata de trabajadores contratados en origen, por lo que el resto de la población inmigrante queda en un terreno de indefinición legal.

El aumento de la productividad y los réditos derivados del aprovechamiento de la mano de obra temporera favoreció profundizar en este modelo desde finales del siglo pasado. No obstante, el crecimiento llegó a colapsar la oferta de servicios estructurales ya en la campaña de 2008/2009, provocando situaciones de emergencia social en las que resultó cotidiano la visión de inmigrantes sin trabajo ni hogar, vagando por las calles de las ciudades jienenses (Menor, 2011).

Localizada en este contexto, Úbeda cuenta con 34835 habitantes según el padrón continuo de población a 1 de enero de 2016. Constan en el padrón 871 extranjeros, de los que un $40 \%$ provienen de Europa (mayoritariamente Rumanía), 32\% de África (mayoritariamente Marruecos), 16,5\% de América y 11,4\% de Asia (mayoritariamente China). Dispone de 28000 hectáreas de olivar inserto en la vía de mayor concentración de este tipo de cultivo (Menor, 2011) en la provincia. En sus terrenos se genera una intensa actividad agrícola entre noviembre y febrero, con motivo de la recogida de la aceituna. Esta actividad deja, al menos en parte, constancia en las altas a la Seguridad Social. Así, según datos del Ministerio de Empleo y Seguridad Social relativos a los meses de octubre de 2016 a marzo de 2017 (un mes antes y uno después del grueso de la campaña en la recogida de aceitunas) se observa un incremento notable en los meses de campaña: mientras que el régimen general de la Seguridad Social recibe un número de altas sistemáticamente situado en casi las 6000, el régimen agrícola duplica la cantidad de algo más de 1000 a algo más de 2000 para el mes de diciembre, bajando sensiblemente a algo más de 1500 en enero y retomando la cuantía inicial en febrero. Esta información da cuenta del trabajo temporero con una clara cobertura institucional. Esta cobertura implica el empleo de trabajadores en situación de regularidad legal, su alta en la Seguridad Social y el acceso a un alojamiento, pues la normativa obliga a los empleadores a facilitar la satisfacción de esta necesidad.

No obstante, es difícil e impreciso estimar el número de personas que se acercan a la ciudad con la esperanza de encontrar trabajo, sin cumplir con la situación de regularidad legal, por lo que deberán encontrar por sus propios medios un lugar donde pernoctar, así como vías para alimentarse, asearse, lavar la ropa y dejar sus pertenencias. Algunas de estas personas utilizarán los servicios del albergue municipal. Para la recién finalizada campaña 2016/2017, se reportan 754 usuarios durante un total de 2549 pernoctaciones. ${ }^{3}$ El resto acudirá a otros cobijos, como portales, la estación de autobuses o cajeros automáticos interiores. Cáritas suministró para esta misma campaña prendas de ropa a 239 temporeros solicitantes y una media de 17 desayunos y 82 cenas diarias. Por parte del Área de Asuntos Sociales del Ayuntamiento de Úbeda, se ofrecieron también almuerzos y cenas, con un pico en el mes de diciembre de 1246 servicios. Algunos autores de este trabajo han participado en rondas nocturnas por las calles de Úbeda, repartiendo mantas y alimentos a quienes se encuentran insertos en este doble proceso de exclusión. 


\section{Estudio empírico. Antecedentes y método}

Con el objetivo de colaborar en el diseño e implementación de soluciones, a partir del diagnóstico de la situación, los autores de este trabajo iniciaron un proyecto de investigación-acción participativa interuniversitario en noviembre de 2015, que continúa hasta la fecha. Dado que la iniciativa se lleva a cabo desde el contexto universitario, adoptó la concreción de las unidades de acción comprometidas-UAC (Manzano-Arrondo, 2012; Manzano-Arrondo y Suárez, 2015). Toda UAC queda definida por la combinación de objetivos de (1) cambio social, (2) aprendizaje y (3) estrategias de comunicación, en los que participan, desde una perspectiva dialógica, al menos la población afectada y la universidad. El equipo configuró una unidad de muy amplio espectro, inserta en la motivación de solucionar de forma estable la situación descrita. Dentro de esa unidad, y siguiendo la lógica del modelo, se anidan otras con la misma estructura. Este trabajo se refiere a una UAC cuyo diseño se explicita en el Cuadro 1. En este marco, la experiencia se refiere a los puntos 2-6 y 9-14.

\begin{tabular}{|c|c|c|}
\hline Elemento & Subelementos & Concreciones \\
\hline \multirow[t]{3}{*}{ Qué } & Cambio social & $\begin{array}{l}\text { 1. Estimular la creación de un grupo de trabajo común entre los diferen- } \\
\text { tes agentes implicados, que se comprometa en el diseño e implementa- } \\
\text { ción de soluciones. } \\
\text { 2. Sensibilizar al estudiantado universitario mediante el contacto directo } \\
\text { con esta realidad. } \\
\text { 3. Visibilizar el problema. }\end{array}$ \\
\hline & Aprendizaje & $\begin{array}{l}\text { 4. Comprender qué está ocurriendo, desde la óptica de los diferentes sec- } \\
\text { tores (migrantes, administraciones y universidad). }\end{array}$ \\
\hline & $\begin{array}{l}\text { Estrategias de comunica- } \\
\text { ción }\end{array}$ & $\begin{array}{l}\text { 5. Elaborar informes, publicaciones y guías, en función de los agentes a } \\
\text { los que van destinados. }\end{array}$ \\
\hline \multirow[t]{4}{*}{ Quién } & Población afectada & 6. Inmigrantes y población autóctona. \\
\hline & Sociedad civil & 7. Organizaciones diversas, como Cruz Roja y hermandades. \\
\hline & Administraciones públicas & 8. Ayuntamiento. \\
\hline & Universidad & $\begin{array}{l}\text { 9. Estudiantes y profesorado de diversas asignaturas y cursos de SAFA, } \\
\text { centro adscrito a la Universidad de Jaén. } \\
\text { 10. Estudiantes y profesor de la asignatura "Metodología Cualitativa" de la } \\
\text { Facultad de Psicología de la Universidad de Sevilla. }\end{array}$ \\
\hline \multirow[t]{3}{*}{ Cómo } & Diseño & $\begin{array}{l}\text { 11. Reuniones entre los agentes. } \\
\text { 12. Constitución de un grupo específico de metodología (GEM) a cargo } \\
\text { de profesorado de ambas universidades. }\end{array}$ \\
\hline & Recogida de datos & 13. Realización de cuatro grupos focales. \\
\hline & Aplicación & $\begin{array}{l}\text { 14. Análisis de resultados por parte de GEM. } \\
\text { 15. Reuniones de interpretación y discusión con los agentes. } \\
\text { 16. Realización y divulgación de los informes específicos. }\end{array}$ \\
\hline Cuándo & $\begin{array}{l}\text { Fase 1: reuniones previas: } \\
\text { Fase 2: constitución GEM: } \\
\text { Fase 3: diseño de la UAC: } \\
\text { Fase 4: recogida de datos: } \\
\text { Fase 5: aplicación: }\end{array}$ & $\begin{array}{l}\text { de noviembre de } 2015 \text { a marzo de } 2016 . \\
\text { febrero de } 2016 . \\
\text { de marzo de } 2016 \text { a septiembre de } 2016 \text {. } \\
\text { noviembre de } 2016 \text {. } \\
\text { desde febrero de } 2017 \text { (fase abierta). }\end{array}$ \\
\hline
\end{tabular}

Cuadro 1. Diseño de la UAC para abordar la realidad inmigrante temporera en Úbeda. Fuente: Elaboración propia. 
En noviembre de 2015 tiene lugar en el centro de educación superior SAFA de Úbeda, adscrito a la Universidad de Jaén, un taller de aprendizaje sobre el diseño y realización de UAC. A raíz de ello se forma un grupo inicial de trabajo en el que se combinan tres perfiles humanos: (1) experiencia de contacto directo con los inmigrantes temporeros de la aceituna y conocimiento sobre la realidad cotidiana en las calles de Úbeda; (2) experiencias sobre el funcionamiento de SAFA y del universo en el que se inserta, y capacidad de negociación y diálogo; (3) conocimientos metodológicos sobre investigación-acción en general y UAC en particular. Este grupo inicia conversaciones y entrevistas focales con los agentes implicados, especialmente inmigrantes, alcaldía, policía local, Cáritas, Cruz Roja, hermandades y dirección y profesorado de SAFA Úbeda. Como resultado, se pone en marcha un proceso, relativamente lento, en el que van encontrándose puntos de conexión entre agentes y definiéndose posibilidades de investigación y de acción orientadas a comprender y solucionar el problema. La recogida de datos a la que se refiere este estudio en particular se lleva a cabo gracias a la implicación voluntaria de estudiantes universitarias de cuarto curso del grado de psicología, que deciden desplazarse a Úbeda desde la Universidad de Sevilla para aplicar los contenidos de aprendizaje sobre metodología cualitativa, ayudando a mejorar una realidad concreta. En esta línea, moderan los cuatro grupos focales que se han diseñado desde el GEM y transcriben los resultados.

Cada uno de los cuatro grupos estuvo formado por un número variable de 5 a 10 participantes, que expresaron sus experiencias y puntos de vista en sesiones de 47 a 61 minutos, generando finalmente tres horas y media de audios. Para la exposición de las porciones de narrativa, que se realiza en el siguiente epígrafe, se codifican los participantes del siguiente modo: (1) PRx para los componentes del grupo focal de profesorado de SAFA; (2) EPx, estudiantes y personal de administración y servicios de SAFA; (3) INx, inmigrantes de origen mayoritariamente subsahariano y, en segundo lugar, rumano; y (4) AUx, para miembros de la población autóctona.

\section{Estudio empírico. Resultados}

La exposición de los resultados se organiza en tres subapartados que siguen la lógica del discurso emergente desde los grupos focales en torno a los problemas de hábitat. El primer apartado (qué ocurre) se ocupa de describir la situación desde la propia población inmigrante y desde la perspectiva de otros agentes. En el segundo (el albergue), se entra en la comprensión sobre por qué la solución estructural se encuentra infrautilizada a pesar de la necesidad que aparentemente sacia. En el tercero (a río revuelto) se describen los beneficios que reporta el desamparo, que en última instancia ayudan a entender el mantenimiento de la situación en su conjunto.

\section{Qué ocurre}

Se observa una situación generalizada de desamparo, concretada en términos de dificultad para encontrar cobijo, comida, aseo, trabajo y comunicación.

[IN6]: Por la mañana, a lo mejor, a veces, no tiene nada, ni tomar café 
[...]. Y por la tarde tiene que tener algún sitio donde comer y pa duchar también. Yo vine aquí el día 30 y hasta ahora me he duchao una vez y hay una fuente ahí donde puedo ducharme, pero el agua está muy fría y tengo miedo pa que me ponga malo también [...], no hay faena en ningún sitio, donde sale, se engancha para aprovechar algo [...]. , dónde enchufan $p a$ cargar los teléfonos, que uno estaba enchufando y el otro viene y se quita.

[IN3]: Entonces, tanto tiempo en el camino, cuando llega aquí necesita ducharse, necesita descansar un poquito, ¿Dónde descansa? ¿En un banco? ¿En un parque? Está mu mal.

[IN7]: Llega esta hora y no ha comido nada, está con un hambre que vamos, y está viviendo con galletas. Viene alguien y te da algo de galletas o lo que sea. Pero así semana tras semana.

[IN3]: Cada vez más hambre, cada vez más hambre.

Desde la población autóctona, se avala esta descripción:

[AU6]: Ellos vienen y luego se encuentran con la triste realidad de que están aquí igual o peor que en su país, porque aquí no tienen nada, pero tampoco tienen su familia, el apoyo de los suyos [...]. El otro día mismo nos encontramos nosotros uno que llevaba dos días en Úbeda que no tenía nada, nada. Y estaba el pobre pues muy desamparao [...]. Y es que, claro, carecen hasta de lo más imprescindible.

[PR1]: Esa persona lleva, a lo mejor lleva semanas o meses caminando. Ha dejado su familia [...]. está buscando algo mejor, algo que dar.

[EP6]: en la fuente del frente, a las 7:30 [...] están lavándose [...]. Eh, a pulmón, eh, vamos, si hay 2 grados como si hay -2 .

\section{El albergue}

La situación de desamparo sorprende inicialmente al existir una aparente solución para ello: un albergue municipal donde la población migrante puede pernoctar, asearse, dejar sus pertenencias, enchufar los teléfonos móviles, etc. Si bien ocurre que:

[IN3]: tiene un número de plazas y el número seguro que es inferior a necesidades. Hay más gente en la calle que el número de plazas.

No obstante, no parece que el número de plazas en sí sea una buena justificación. Obsérvese la utilización de "seguro que...", recurso al que se acude cuando no se posee experiencia directa y se realizan suposiciones. En otras palabras, IN3 no parece contemplar el albergue como una opción real, sino que ya parte de un conocimiento compartido, tenga o no sustento empírico o vivencial. Las entrevistas previas y el acceso a información directa muestran que el albergue se encuentra sistemáticamente incompleto. Siempre hay plazas libres. Esto desconcierta a otros participantes.

[PR3]: que sorprende que pongan un albergue, donde tienen comida, donde tienen ducha, donde tienen una cama, donde tienen tal... y se nieguen, es decir... que es muy sorprendente... es decir, pero, bueno, vamos a ver, ¿qué prefieres, dormir en el suelo y no poderte duchar, y no tener comida y tal... o sea, prefiere eso?

[AU6]: los que no van al albergue, pues los pobres no saben dónde ducharse, ni lavar la ropa y la ves tendía la ropa ahí en donde están en la estación de autobuses. 
¿Qué explica este bajo nivel de uso de un servicio gratuito y aparentemente efectivo? Existen tres razones para comprender la situación:

1. La limitación de tres días para el albergue. Normativamente, el servicio solo puede ser utilizado durante tres días seguidos, como medida para dar cobertura a más población con menos plazas. Los inmigrantes que encuentran un sitio en un cajero y van al albergue, al finalizar los tres días encuentran que ya perdieron su plaza en el cajero, por lo que prefieren no hacerlo.

[IN6]: Yo, desde que vengo aquí, prefiero dormir en la calle, porque si lo dejas tu sitio en el banco, de dormir tres días antes, ya vuelves y ya otra persona ha estado ahí, entonces tú ya no vas a encontrar ahí un sitio.

[AU8]: ellos no quieren ir al albergue porque pierden sus cajeros.

[EP1]: El albergue como tal solo les permite tres noches, con lo cual, cuando pasan esas tres noches, se ven en la calle. Porque ya no pueden volver a entrar ¿Qué es lo que hacen? Pues ellos, en vez del albergue, prefieren buscarse un cajero, un hueco en una esquina, en... un portal, porque saben que eso lo tienen fijo.

[PR4]: Tú vas allí y pierdes tu sitio preferente que tenías. Vas a un cajero y tienes calefacción, entonces... eso hay que verlo. Si sales del cajero, vas tres días al albergue, cuando vuelves el sitio no lo tienes.

2. Los cajeros se encuentran en situación de más fácil acceso para la ruta de los agricultores empresarios, que reclutan mano de obra por la mañana temprano. El albergue se encuentra lejos y fuera de la ruta.

[IN3]: Si está trabajando a 15 kilómetros de Úbeda no puedes irte todas las mañanas a salir del albergue.

[PR2]: Ellos tienen localizado más o menos los sitios donde a las seis de la mañana pasa un Land Rover, los mete $p a$ dentro [chasca dedos] y se los lleva. Vamos, entonces, si no están ahí, no hay trabajo. Y el albergue está en el quinto cipote, todo lo tienen que hacer andando.

[AU6]: Ellos buscan, pues, los sitios donde ellos pueden ver a la gente que los pueden contratar.

3. Coherencia con la ilegalidad. Por otro lado, buena parte de esta mano de obra es ilegal. El albergue otorga carta de oficialidad al reclutamiento, mientras que los cajeros se instalan mejor en la dimensión oculta. Los empresarios se sienten menos vulnerables si reclutan en los cajeros que en zonas más visibles y oficiales. Por parte de los inmigrantes ocurre lo mismo: se sienten menos vulnerables fuera de lo institucional cuando no tienen papeles. Incluso algunos duermen bajo los olivos.

[PR1]: Hay gente que, incluso... hay grupitos que incluso... y se iban a vivir en medio de las olivas, ni dentro de la ciudad. También por miedo y porque la policía, a lo mejor, muchas veces a lo mejor estaba dando vueltas y ellos no sabían si les iban a pedir determinada documentación.

[PR2]: Preferían dormir en un cajero que... ¿cómo puede ser?... pues claro puede ser. Puede ser porque ellos tenían localizados los sitios, que esa es otra, donde los cogen para ir a trabajar, y ahí, claro, los cogen en $\mathrm{B}$, no los cogen legalizados. 


\section{A río revuelto...}

La situación de vulnerabilidad se asienta, entre otros aspectos, sobre la consideración instrumental que el propio inmigrante temporero tiene sobre sí y que favorece aceptar condiciones especialmente penosas:

[AU2]: porque ellos la necesidad más grande que tienen es trabajar, que por eso están aquí, porque trabajan para los que están allí que se mueren de hambre.

De este modo, la extensa demanda de empleo, la ausencia de contratos y la necesidad imperiosa de obtener alguna cantidad de dinero por parte de la población migrante permite a los contratadores conseguir mano de obra en condiciones de claro desequilibrio.

[IN7]: a veces, algunos jefes que necesitan aprovechar con su trabajador, si tú no aceptas y tienen, echarte fuera y buscas la vida de otra manera, otra vez [...] tienes problema con jefe y no puedes decir ni pío, está esclavizado para hacer ese trabajo. No puede levantar la cabeza para decir este sí o este no, tiene que hacer trabajo como él manda [...]. Te puede decir jefe bueno, que te voy a dar 6 horas o 7 horas, 53 euros.

[PR3]: ilegalmente. ¿Estamos? Entonces los tratan como esclavos.

[EP1]: luego si te pasas a partir de las cinco de la tarde, que se acaba la jornada y demás, te los encuentras viniendo andando.

[EP5]: Y lo triste no es eso, lo triste es que ahora pase lo que sea en cualquier campo de oliva, se rompen una pierna porque se le caiga lo que sea y el hombre coge el coche y lo deja en la estación y aquí yo no sé nada.

Considerando esta situación de desequilibrio, durante el transcurso del grupo focal con la población migrante, tanto el personal entrevistador como un informador externo a la investigación, preguntaron a los participantes por sus derechos y la cobertura laboral.

[Entrevistador]: ¿Y vuestros jefes? La persona a la que le trabajáis, ¿no os proporciona alojamiento ni nada? ¿ni comida ni nada? [Participantes]: No.

[Entrevistador]: las tablas salariales, por ejemplo, tantas horas equivale a tanto dinero. Eso, ¿lo llegáis a conocer? [IN7]: A esto más vale que no se lo enseñemos al jefe [ríe], más vale que no se lo enseñemos [murmullo]. Aunque sea que ya entiendo un poco la pregunta, este sabe un poquito sus derechos, ¿la persona que enseña un poquito sus derechos no? Más vale que no sepa al jefe, si no no te va a contratar. Un día, dos días, cuanto tú preguntas tu jefe tu salario o lo que sea te va a decir, bueno, mira, la puerta está abierto, busca la vida por fuera.

[Informador]: Ustedes deberían ir también a los sindicatos, está UGT y Comisiones Obreras, hay mucha gente dispuesta... Me ha surgido la idea de a lo mejor os reunamos a todos aquí y que os informen de vuestros derechos y deberes, de cómo deben ser los contratos... no sé, se me ha ocurrido antes... y si alguien me hace caso os podemos convocar para que os informen de lo que yo os estoy contando... [IN3]: Todo eso nos va a traer más cosas malas... [hablan a la vez] [IN3]: Si yo voy a esa reunión y se enteran que me he metido en un sindicato, mañana ya no tengo trabajo.

En definitiva, la experiencia para los inmigrantes en situación de irregularidad legal consiste en hacerse visible para los empleadores, escuchar su oferta y aceptar las condiciones o esperar la oferta de otro 
empleador. Las condiciones explícitas se ciñen a la cantidad que va a recibir a cambio de las horas de trabajo que ha de realizar. Las condiciones implícitas tienen dos caras. Por un lado, el empleador se desentiende de todo lo demás (modo de volver a la ciudad, alojamiento, comida, asistencia en caso de accidente, etc.); por otro, el empleado no va a dar problemas de ningún tipo. Este acuerdo parece cumplirse sin más problemas en la práctica.

[IN6]: El jefe paga todas las horas, cuando lo promete te paga [...]. Algunos pagan más, algunos pagan menos, pero cuando dicen cincuenta es cincuenta, cuando dicen sesenta es sesenta.

Las condiciones laborales constituyen el núcleo de un sistema que instrumentaliza a la población inmigrante al menos en dos sentidos: como fuente de réditos monetarios y como medio para generar algún provecho de otro tipo, de tal forma que no se trata de una ayuda hacia el inmigrante, sino de un uso interesado de su existencia. Así, por ejemplo, algunos empleadores van más allá en la explotación del desequilibrio:

[IN6]: Yo el año pasao, yo trabajo 47 días, con una persona te da la casa, pero cuando termina, tenía 4 personas cada una ha descuentao 300 euros, agua, la luz y la casa.

[AU6]: ellos por lo menos se desahogan con nosotros y ellos comentan que gente de Úbeda que tiene olivas dicen "te arreglo los papeles, pero me tienes que dar tanto, me tienes que echar tantos jornales". Dicen que pagaban hasta 1000 euros por arreglarle los papeles el empresario.

Los réditos monetarios tienen más beneficiarios:

[EP1]: hay mafias que se dedican a cobrar. Claro, les buscan el billete de autobús, les buscan no sé qué, y, claro, una pequeña comisión, entre comillas lo de pequeña y los mandan para acá. Diciéndoles que no se preocupen, que aquí hay trabajo, que no hay problemas, y, claro, se lo quitan de encima, lo mandan aquí, y cuando llegan aquí se encuentran que todo el mundo está ya colocado.

[PR2]: se organizaron auténticas mafias para e incluso cobrar por el cajero, o en la comunidad tal, eh... entre ellos mismos tienen mafias... [...], yo te puedo decir un número importante que cobran por estar en un cajero.

No obstante, al preguntar expresamente sobre ello, la respuesta es:

[IN3]: No, no, eso no pasa, que yo sepa, vamos... y no creo que nadie se haya metío en un cajero para alquilar un [inaudible] para dormir... yo no he escuchado nunca.

La instrumentalización se ha mostrado también en situaciones donde no interviene directamente el beneficio económico:

[IN7]: alguno viene con la ropa, pero necesita una grabación para sacar algo, no sé, pero de verdad, que ni siquiera [...], porque viene y tiene que regalar unos pantalones y encima quiere grabarte porque va a salir en algún periódico o lo que sea. Pero eso no es una ayuda, eso es una cosa que se le llama intercambiar. 
[PR2]: Yo me acuerdo, ya el colmo de los colmos fue cuando nos traen un autobús, eh... aquí a la parroquia y con Canal Sur detrás [...]. Venía él, venían todo el autobús de inmigrantes y venía Canal Sur detrás, porque creían que el párroco les iba a cerrar las puertas [...]. Nosotros nos quedamos toda la noche por acompañar a esta gente, que estaba siendo manipulada.

[PR2]: ¡Los partidos políticos están utilizando a estas criaturas, así! Para arrojarse toda la porquería que tienen que arrojarse. Pero con fines políticos. Yo creo que no les importa. Imagino que así, de forma global, estoy diciendo a lo mejor una barbaridad, pero es lo que pienso.

La instrumentalización no se ciñe a la búsqueda de algún tipo de rédito, sea económico o político, sino también a evitar perjuicios derivados de la presencia inmigrante:

[EP1]: La administración local se los quita de encima. ¿Y cómo se los quita de encima? Les paga un billete de autobús al siguiente... al siguiente pueblo.

[PR2]: Dentro de la comarca en la que nosotros nos movemos el hecho de que existan localidades que retrasan la apertura de un albergue... eh, lo están haciendo así... pero, vamos, de una forma totalmente pensada y repensada para desviar gente a otros lados, o sea, que esto se hace.

\section{Conclusiones}

Los resultados cualitativos que se han organizado en el epígrafe anterior dibujan con claridad un notable estado de vulnerabilidad generalizado en torno a la población inmigrante que acude a Úbeda con el objetivo de participar laboralmente en la recogida de la aceituna, sin contar con una cobertura estructural. La situación no solo afecta a la necesidad de una vivienda digna, sino que este déficit colabora intensamente en la profundización de la exclusión social de este sector de la población, de tal forma que la fuerte vulnerabilidad eclosiona en muchos casos en la forma de sinhogarismo.

\section{Sinhogarismo inmigrante en Úbeda}

Las informaciones previas permiten identificar dos situaciones de acogida. Por un lado, se encuentran los inmigrantes con plena cobertura legal, que lleva aparejada el alta en la Seguridad Social, un sueldo o contraprestación económica sujeta a las disposiciones legales y la resolución del alojamiento. Por otro, existe un abanico diverso de circunstancias que configuran grados también diversos de marginación, todos ellos en torno a una situación de amparo estructural notablemente incompleto e insuficiente. La situación menos perentoria está caracterizada por inmigrantes que no cuentan con una regularización documental que les permita formar parte del primer grupo, pero que consiguen un trabajo para toda la campaña, que pueden aprovechar el tiempo limitado de uso del albergue hasta encontrar un alojamiento estable (quizá en el propio campo de aceitunas donde trabajan) y que reciben un sueldo dispuesto unidireccionalmente por el empleador, pero que garantiza la supervivencia y posiblemente la generación de algún remanente o ahorro.

En el extremo de la exclusión se encuentran quienes sufren una si- 
tuación de desamparo estructural, cuya descripción ha copado en buena parte las aportaciones en los grupos focales. Se trata de un colectivo amplio que decide no utilizar los albergues por implicar una visibilidad que pone en peligro su búsqueda de trabajo y por encontrarse fuera de las vías de los empleadores que prefieren obtener mano de obra en los cajeros. No cuentan con medios suficientes para llevar una vida mínimamente digna. Padecen problemas de aseo, alimentación, descanso, frío y serias dificultades para dejar sus escasas pertenencias o para solventar otras necesidades. Un ejemplo de estas es cargar la batería del teléfono móvil, un instrumento que les permite el contacto con las familias y con quienes pueden informarle de otras campañas agrícolas $u$ otras oportunidades. Esta población altamente vulnerable resulta muy atractiva para quienes ofertan condiciones laborales abusivas, centradas únicamente en el intercambio de trabajo por dinero y sin contemplar el resto de aspectos pertinentes como el transporte, la manutención o el alojamiento. La situación de notable desamparo que sufren estimula no solo la tendencia al cuidado, sino también la oportunidad de ser instrumentalizados para fines diversos.

\section{Cinco preguntas fundamentales}

Los grupos focales se ciñeron al asunto de "qué está ocurriendo en estos momentos en Úbeda". Su objetivo no fue entender el fenómeno en un contexto globalizado, lo que incluiría con protagonismo el interés por comprender, por ejemplo, las situaciones de los países y regiones originarias de la población migrante. Debido a esta motivación específica, los resultados de esta UAC no deben interpretarse como una unidad completa de comprensión. Es fundamental situar el fenómeno ubetense en una realidad mucho más amplia. Son las dinámicas internacionales lo que subyace a lo que ocurre en lugares concretos como el analizado. Por este motivo, la interpretación de los acontecimientos en Úbeda exige combinar los fenómenos locales con los globales. Algunas aportaciones concretas en los grupos focales apoyan este enfoque:

[EP4]: Es que a un problema global no le podemos dar una solución local.

[AU2]: La forma de asegurarse es que los países europeos y las alianzas demás... que no invadan sus países, que ellos puedan vivir allí normalmente y que no estén hechos una basura. No cuenten nada allí, porque vayas a explotar sus tierras o sus recursos naturales y esa es la solución, porque yo soy de aquí y no me quiero ir a ningún lao, quiero viajar, quiero ver cosas, pero quizás también quiero estar aquí con mi familia y con mi gente. Luego entonces, ellos, ¿por qué no lo hacen? No es porque sean altruistas ni porque sean, yo que sé, simplemente no lo hacen porque no pueden seguir viviendo allí, no pueden vivir en sus países porque los están explotando, los están invadiendo, los están, puf, eso también hay que comprenderlo, hay que entenderlo, que es que no están aquí por gusto, ni porque les guste más España.

[PR3]: Habría que comenzar a ver la política internacional [...] a nivel nacional, pues políticas, políticas que no pongan vallas, cuchillas, que no pongan tal, o sea que... pero no se va por ahí, no se va por ahí porque cuantas más vallas ponen parece que más te votan.

Diferentes agentes participan por acción u omisión en todo ello. Desde la perspectiva local, quien emigra y llega a la zona de actividad 
agrícola y lo hace en condiciones de irregularidad legal, no parte de una conciencia de derechos, sino de necesidad y precariedad. La necesidad le obliga a aceptar condiciones laborales infradignas, mientras que la precariedad le aconseja mantenerse en el lado invisible y no generar ningún tipo de conflicto. La invisibilidad está fundamentada en el temor a ser identificado y expulsado (Gordo, Felicidades y Menor, 2013). En definitiva, tenemos a un individuo altamente disponible y poco exigente, que no desea dar problemas y que busca solo obtener dinero mediante su fuerza de trabajo. Distanciando el foco, la cuestión fundamental 1 es: ¿qué dinámicas globalizadas provocan la pauperización medioambiental y económica de sus países de origen, llevando a que parte de su población ingrese en los procesos de emigración forzada? La desesperación que caracteriza el proceso explica la situación de vulnerabilidad a niveles individual y relacional con que acceden al lugar de destino, en el que serán recibidos desde un contexto también constructor de vulnerabilidad.

Por su parte, los empleadores con menos escrúpulos observan en la población inmigrante vulnerable una buena oportunidad, no solo para ahorrar gastos directos e indirectos relacionados con la mano de obra, sino para colocar el producto agrícola en el mercado con alguna ventaja competitiva. La cuestión fundamental 2 en este caso es: ¿qué dinámicas globalizadas construyen la especialización zonal, de tal forma que unos pocos puntos del planeta acaparan la producción y comercialización de los productos de alto valor añadido, mientras que las demás zonas quedan confinadas a la función de suministro de mano de obra barata y materias primas de alto riesgo, en contextos donde solo puede competirse mediante la oferta de precios más bajos?

La población autóctona se mantiene difícilmente en un doble discurso. Por un lado, existe una clara tendencia hacia la ética del cuidado, en términos de atender al otro en su situación de vulnerabilidad. Por otro, co-existen (1) miedo ante la competencia de una mano de obra que se ofrece más barata que las condiciones aceptables para la población local, además en un contexto de crisis en el que la población autóctona recupera nichos laborales previamente despreciados (Gordo, Felicidades y Menor, 2013); (2) miedo ante la anormalidad que implica la presencia inmigrante que, a su vez, (3) implica precarizar la tradición, lo convencional o lo conocido; y (4) miedo a reconocer directamente la existencia de pobreza y exclusión en el propio lugar que se habita. Como resultado del dilema entre el cuidado y los miedos, la población inmigrante recibe al mismo tiempo compasión y rechazo, atención y exigencia de invisibilidad. La población autóctona intenta solucionar el dilema culpando a la víctima mediante la intervención de prejuicios que se apoyan en explicaciones culturales o biológicas (Mazzara, 1999) y cuya función discursiva es librarse de la culpa. Por ello, la cuestión fundamental 3 es: ¿qué dinámicas globalizadas construyen los mitos y discursos hegemónicos en torno al funcionamiento del mundo, mediante la invisibilización de los procesos y la extensión de explicaciones simples y reducidas que descargan sobre las víctimas la responsabilidad de su situación? Esos mitos favorecen el triunfo de una especie de gafa capitalista que ve con buenos ojos el tránsito de turistas con poder adquisitivo, pero ejerce un fuerte e inhumano control sobre el movimiento de quienes se mueven como resultado del poder adquisitivo del resto (Soto, 2007).

Las administraciones públicas reaccionan con dificultad ante esta realidad. La construcción de albergues constituye un indicador de in- 
terés por realizar acciones que solucionen o reduzcan la gravedad del problema de vivienda. No obstante, la notable insuficiencia de esta medida descubre un referente de trabajo político que puede definirse del siguiente modo: (1) instalación en el discurso de la escasez, según el cual las administraciones han de partir de unas notables limitaciones monetarias y legales que no se discuten y que resultan insuficientes ante la demanda; (2) clasificación de los demandantes en legales e ilegales, priorizando la atención a los primeros; (3) reto de dar respuesta a dos peticiones incompatibles que provienen del mismo electorado: atender a una situación inhumana; al mismo tiempo, economizar los recursos disponibles para cubrir otras exigencias, e incluso, mostrar ante el electorado una clara posición de protección de "los nuestros" frente a "los otros". Aquí, la cuestión fundamental 4 es: ¿qué dinámicas globalizadas, implementadas en prácticamente todos los territorios, han construido y mantienen una dinámica de relación entre administración y ciudadanía que no solo se nutre de los mitos de la escasez, la meritocracia y el nosotros-ellos, sino que confina el papel político del ciudadano-modelo al de participación en los actos electorales y a exigir mediante los medios de comunicación soluciones parciales?

Por último, la universidad juega en este asunto mediante la omisión. Ya se ha denunciado en numerosas ocasiones que la institución de educación superior se comporta básicamente como mantenedora del statu quo (Apple, 2011; Benítez, 2012; Ellacuría, 1999; Greenwood, 2012). Una institución especializada en el conocimiento debería desempeñar un papel activo muy diferente. Por un lado, se deduce de los párrafos preferentes que las respuestas a las preguntas fundamentales sobre las dinámicas globales exigen una intervención analítica profunda y fundamentada, que constituye la impronta identitaria de la universidad. Por otro lado, en su seno se forman quienes posteriormente ocuparán las posiciones de mayor influencia social. Debido a ello, resulta del todo necesario incluir en los diseños curriculares una mirada global que permita comprender los fenómenos locales, especialmente las disfunciones de un sistema que termina comportándose de forma notablemente injusta con las poblaciones más vulnerables, a la vez que construyendo efectivamente vulnerabilidad. La universidad no está desempeñando esa función; luego he aquí la cuestión fundamental 5: ¿qué dinámicas globalizadas configuran una universidad que funciona según un modelo productivo en torno a egresados, publicaciones y otros outputs medidos cuantitativamente, y que sigue desatendiendo la interpretación fundamentada de la realidad cotidiana, la formación de profesionales con impronta de justicia global y la propuesta científica de soluciones a problemas tan acuciantes como los que justifican esta UAC?

\section{Desde y hacia la complejidad}

"Todo buen conocimiento se levanta sobre un sistema de preguntas" (Wagensberg, 1985, p. 18). En coherencia con ello, los cinco interrogantes del epígrafe anterior acotan cinco dimensiones de actuación, con sus respectivos protagonistas y mecanismos de funcionamiento. No puede comenzar a diseñarse ninguna solución creíble si no se pone sobre la mesa la relación compleja entre tales dimensiones. A saber: (1) el deterioro medioambiental y social que castiga con dureza a unas zonas del planeta, cuyas poblaciones ingresan en las dinámicas de migración forzada; (2) la especialización económica globalizada que cons- 
truye procesos de esclavitud que afectan a las funciones de producción, consumo y empleo; (3) el protagonismo de mitos ideológicos que fundamentan la desigualdad y la ignorancia mediante imágenes estereotipadas sobre el funcionamiento del mundo; (4) el anquilosamiento de una versión desvirtuada de la democracia, que esclaviza a partidos y electores en estéticas de participación y, a la par, "sometimiento a" y "construcción de" opinión pública; y (5) el sistemático abandono por parte de la universidad, respecto a su función potencial de institución del conocimiento preparada para diagnosticar, explicar y proponer modelos de intervención acordes con una realidad compleja.

Autores como Morin (1995) o Vilar (1997) han criticado de forma contundente el modo en que es frecuente tomar decisiones políticas, basadas en enfoques simples, pero aplicadas en entornos complejos. De este modo, tales decisiones suelen atender a una parte de la realidad, desatendiendo otras y generando en ocasiones efectos contraproducentes. El hábito ha quedado naturalizado, de tal forma que, en palabras de Wodak (2003), "existe la percepción de que los fenómenos complejos necesitan respuestas simples" (ob. cit., p. 101). Torres (2011) aplica esta crítica general a los problemas de hábitat, contexto en el que frecuentemente se articulan supuestas soluciones que terminan empeorando la situación o dificultando soluciones posteriores.

No solo es necesario diagnosticar el problema desde sus múltiples caras, sino que el diseño de las soluciones requiere a su vez la participación de lo que Méndez (2009) denomina "las diferentes culturas del saber". En coherencia y respecto al sinhogarismo inmigrante, es imprescindible que participe la universidad, la administración pública, las ONG, los agentes empleadores y los colectivos o grupos ciudadanos, tanto de inmigrantes como de población autóctona. Es lo que Manzano-Arrondo (2012) describe en términos de intertransdisciplinariedad: diferentes disciplinas y sectores académicos confluyen con agentes no académicos en torno al diseño y ejecución de soluciones. Cada agente colectivo aporta una "cultura del saber" y enriquece la visión compleja del asunto, añadiendo garantías para creer en las soluciones que se diseñan. En cualquier caso, la confluencia de todos los agentes con un papel fundamental en el asunto tampoco garantiza una buena solución, pues nada realmente complejo puede ser comprendido en su totalidad (Pryor y Bright, 2004). Por ello, hay que partir de una postura humilde que aconseja ensayar soluciones desde una visión estratégica a largo plazo e ir evaluando en tiempo real los efectos. En la confluencia de todo ello, el enfoque de solución que se plantea desde esta UAC se inspira en lo que García Roca (2001) denomina "metáfora de la navegación": no hay soluciones concretas, cuantitativas, perfectamente acotadas, sino una carta de navegación, un rumbo y un conjunto de pautas útiles para tomar decisiones en el camino. En nuestro caso, los siguientes puntos derivados de los anteriores interrogantes, y ya contemplados en el diseño de la UAC, muestran pautas de actuación concretas y estilos también concretos para la navegación.

1. Apuntar a construir soluciones efectivas y ejemplares a nivel local. Aunque este nivel se muestra insuficiente para abordar con éxito el cambio de las dinámicas globales, responde bien a la estrategia de abajo arriba que Codina y Delgado (2006) proponen para abordar problemas complejos. Las experiencias de éxito parciales y locales sirven, además, como medida de presión, de fuerza o de proposición, para actuar sobre instancias de mayor amplitud. 
2. Comprometer a todos los agentes implicados en la situación. Por este motivo, la UAC se ha diseñado y se está desarrollando con la participación de la universidad, ONG locales, la administración pública y representación de inmigrantes y de población autóctona. El compromiso de los diferentes agentes, que a su vez garantiza la presencia de enfoques y vivencias diferentes, sacia en parte la propuesta de los triángulos en la gestión social del hábitat (De Manuel, 2010), como enfoque complejo para abordar problemas complejos. No obstante, falta la presencia de los empleadores, deficiencia importante que limita y dificulta, pero no imposibilita.

3. Implicar a especialistas diversos. Como se ha destacado en numerosas ocasiones (por ejemplo, Butterfield y Korazim-Korösy, 2007), el trabajo en entornos comunitarios requiere un enfoque transdisciplinar que, a su vez, requiere la participación horizontal de especialistas en áreas diferentes. Entre los miembros del equipo se encuentran personas formadas en psicología, economía, educación y trabajo social. El equipo no es estático y atrae el interés de otros especialistas.

4. Trabajar un enfoque educativo. En términos de educación formal, la UAC implica una perspectiva de aprendizaje-servicio (Speck, 2001), lo que está afectando al currículum de asignaturas concretas en dos universidades andaluzas. En términos de educación no formal e informal, se requiere una labor de autoaprendizaje de los agentes implicados y de educación específica orientada a la ciudadanía, para revertir los efectos de los procesos globalizados mencionados que construyen ignorancia, miedo y sentimiento de amenaza (Morin, 1995; 2001).

5. Trabajar un enfoque ideológico. La ideología es un ente inevitable, construido como resultado de una permanente conversación entre cada individuo y el marco discursivo que ha elegido, o que le ha elegido, y que define una forma concreta de interpretar el mundo, de preferir un mundo antes que otro y de actuar en él (Manzano-Arrondo, en prensa). Ya se ha indicado más atrás que las dinámicas globalizadas construyen y mantienen discursos potentes y efectivos, que ayudan a mantener la situación de injusticia por la que finalmente transita el sinhogarismo inmigrante. Por tanto, las actuaciones de los agentes de cambio deben ir también orientadas hacia un trabajo ideológico, en el sentido de trastocar los referentes interpretativos, transitando desde la amenaza a la oportunidad, desde el desequilibrio a la igualdad, desde la ignorancia al conocimiento, etc.

6. Practicar el contacto directo. La distancia perpetúa el tratamiento diferencial e injusto del otro (Montero, 2005) que, a su vez, justifica mantener la distancia. Para revertir el ciclo, no solo el equipo trabaja codo con codo con las víctimas del sinhogarismo inmigrante, sino que la intervención favorece que los diferentes agentes de cambio conozcan esa realidad en directo.

\section{Discusión}

Las porciones de narrativa extraídas de los diferentes grupos focales muestran un panorama complejo, pero claro, donde diferentes agentes desempeñan un papel importante en el mantenimiento de una situación de desamparo. Esta situación deriva finalmente en el perjuicio 
directo de los inmigrantes temporeros, y en el indirecto para la sociedad ubetense en su conjunto. En esta línea, Paloma y Manzano-Arrondo (2011) destacan que la existencia de grupos oprimidos o receptores de perjuicios, más que beneficiar directamente a los grupos opresores o receptores de beneficios, terminan perjudicando profundamente a la sociedad que alberga estas dinámicas, por lo que la solución que mejor beneficia a medio y largo plazo, promoviendo no solo justicia sino también bienestar, es terminar con los procesos de desequilibrio. Para trabajar en esta línea es importante insistir, en todos los discursos, que la integración de la población inmigrante no es un problema que atañe a quienes llegan desde los procesos migratorios, sino a toda la sociedad (García-Ramírez et al., 2011).

El sinhogarismo inmigrante no es un fenómeno incomprensible que emerge de un funcionamiento sistémico difícil de identificar. Muy al contrario, se asienta sobre elementos claramente distinguibles. Hablamos de personas que ya partían de una situación vulnerable desde sus países de origen; situación provocada por funcionamientos globalizados. Esos mismos funcionamientos participan en todo el proceso de emigración, generando abundantes barreras físicas y políticas, que muchas personas no superan, pereciendo en el camino. Quienes llegan a las poblaciones de destino ven en muchos casos frustradas sus aspiraciones de bienestar y justicia, instalándose en la invisibilidad social (Sánchez y Tezanos, 2004), de tal forma que la vulnerabilidad se asienta al margen de la legalidad, pero reforzada por ella.

La solución al desamparo puede ceñirse exclusivamente a la dimensión de la ética del cuidado o puede adoptar la forma de medidas legales mediante la consideración oficial de sujetos de pleno derecho a quienes no se encuentran amparados por papeles, así como la consideración de la vivienda como derecho fundamental protegido por las instituciones públicas. En otros términos, o bien se establece una cobertura legal que extrae de la situación de ilegalidad a toda persona inmigrante, sin considerar excepciones; o bien se establece una cobertura institucional que garantice la aplicación efectiva de un único principio de cuidado: nadie debe quedar en situación de desamparo en la sociedad receptora.

Es importante asumir que esta UAC ha centrado su análisis en una realidad que no es extensiva a toda la situación ubetense en torno a la recogida de la aceituna. Los inmigrantes que formaron parte del grupo focal específico se encuentran mayoritariamente en la situación de sinhogarismo. Por otro lado, los integrantes del resto de los grupos focales situaron su atención en la cotidianidad más marginada, por ser la que requiere una intervención más urgente. Estos datos se refieren, por tanto, al aspecto de la realidad en la campaña de la aceituna que debería exigir una intervención más urgente, pero no deben ser considerados como la tónica o la norma necesariamente. En ese sentido, este trabajo no debería interpretarse como una descripción de todo cuanto ocurre o de lo que resulta estadísticamente más representativo, sino como una descripción e interpretación de acontecimientos que ocurren efectivamente y de los condicionantes que los rodean. Todo ello apunta a un funcionamiento sistémico que debe ser corregido.

Ya se ha mencionado en diversas ocasiones que la situación es compleja por cuanto afecta a múltiples intereses, dimensiones, agentes y escalas. Ello se utiliza para justificar medidas parciales, insuficientes o incluso contraproducentes, arguyendo que la complejidad del problema hace difícil la solución (Lora-Tamayo, 2003). Sin embargo, la difi- 
cultad puede ralentizar los procesos y aumentar las exigencias de participación y de recursos, pero no impide abordar con determinación el problema y resolverlo. La dificultad, además, ha ido justificando hábitos de actuación que cubren la estética de la responsabilidad, pero que no se orientan efectivamente a las soluciones. Así, por ejemplo, se ha protagonizado el discurso en torno a la legalidad/ilegalidad de las personas, en lugar de protagonizar el respeto y promoción de los derechos humanos (Guillén, Lucas, Pérez y Arias, 2001; Soto, 2007). En la reversión de los procesos se requiere la participación de todos los agentes implicados y una actitud clara para abordar el problema desde su condición estructural y sin rodeos (Soto, 2007). Esta participación es difícil e incluso improbable en muchos casos, dado que los procesos que confluyen ubican fuertemente a cada agente en un nicho cerrado que dificulta la colaboración. Las poblaciones autóctona e inmigrante, las administraciones públicas, los medios de comunicación y los empleadores se encuentran frecuentemente atrapados en procesos en los cuales un movimiento emancipador $\mathrm{u}$ orientado hacia la solución del problema es poco probable. Lo es no solo porque llega a ser difícilmente visible, sino porque una vez visibilizado choca frontalmente con las prácticas establecidas; prácticas en las que cada agente siente protegido su estatus. Las cinco preguntas fundamentales a las que da forma un epígrafe previo tienen la misión de aislar los procesos que dificultan el cambio sistémico. En todo ello, la universidad debería jugar un papel protagonista. Y debería hacerlo no solo porque hoy en día la educación no puede ser pensada sin considerar los procesos de globalización (Apple, 2011), sino porque la universidad instala su cotidianidad en una posición de relación privilegiada con el conocimiento. Por ello, puede y debe generar el conocimiento que es necesario para (1) comprender qué ocurre, (2) diseñar y fundamentar medidas y (3) guiar a los agentes implicados en la implementación de las soluciones. 


\section{Referencias}

Apple, M.W. (2011). Global crises, social justice, and teacher education. Journal of Teacher Education, 62, 222-234. DOI: http://dx.doi. org/10.1177/0022487110385428.

Benítez, M. (2012). Propuesta para una academia alternativa. En Báez, R. (ed.), Universidades: entre la mercadofilia y la alterglobalización. Quito: Gallo Rojo. Centro de Pensamiento Político, pp. 32-36.

Butterfield, A.J. y Korazim-Korösy, Y. (2007). Interdisciplinary community development: Setting the future course. Journal of Community Practice, 15, 239-245. DOI: http://dx.doi.org/10.1300/J125v15n01_11.

Cabrera, P.J. (2009). La exclusión residencial severa. $\mathrm{El}$ caso de las personas inmigrantes sin hogar. $M U$ GAK, 46, 1-4.

Camps, V. (2000). Los valores de la educación. Madrid: Anaya.

Checa, J.C. y Arjona, A. (2006). Segregación y condiciones residenciales de los inmigrantes africanos en Almería (España). Migraciones Internacionales, 3 (3), 81-106.

Codina, S. y Delgado, C.J. (2006). La revolución contemporánea del saber y la complejidad social. Buenos Aires: Consejo Latinoamericano de Ciencias Sociales.

De Manuel, E. (2010). Construyendo triángulos para la gestión social del hábitat. Hábitat y Sociedad, 1, 13-37.

Ellacuría, I. (1999). Escritos Universitarios. San Salvador: UCA Editores.

Estefanía, J. (2001). Hij@, ¿qué es la globalización? La primera revolución el siglo XXI. Madrid: Aguilar.

García, J. (2001). La navegación y la fisonomía del naufragio. El aspecto moral de las profesiones sociales. En Kisnerman, N. (ed.), Ética, ¿discurso o una práctica social? Buenos Aires: Paidós, pp. 15-43.

García, J.A. (2015). Concepto de vulnerabilidad psicosocial en el ámbito de la salud y las adicciones. Health and Addictions. Salud y Drogas, 15 (1), 5-14.

García-Ramírez, M. et al. (2011). A Liberation Psychology approach to acculturative integration of migrant populations. American Journal of Community Psychology, 47 (1-2), 86-97. DOI: http:/ /dx.doi. org/10.1007/s10464-010-9372-3.

Gordo, M., Felicidades, J. y Menor, J. (2013). Temporeros extranjeros en la campaña de la aceituna de Jaén: el actual contexto de crisis y sus repercusiones en la red de albergues. En Camacho, J.A. y Jiménez, Y. (eds.), Desarrollo sostenible en tiempos de crisis. Granada: Universidad de Granada, pp. 821-843.

Greenwood, D.J. (2012). Doing and learning action research in the neo-liberal world of contemporary higher education. Action Research, 10, 2, 115-132. DOI: http://dx.doi. org/10.1177/1476750312443573.
Guillén, E. et al. (2001). Servicios sociales e inmigración: límites y retos para una nueva política social. Alternativas. Cuadernos de Trabajo Social, 9, 211-239. DOI: http://dx.doi.org/10.14198/ALTERN2001.9.11.

Hildegard, M.R. (2012). En los límites de la exclusión social. Inmigración y sinhogarismo en España. $P a$ pers, 97 (4), 829-847.

Hollomotz, A. (2012). Disability, oppression and violence: towards a sociological explanation. Sociology, 47 (3), 477-493. DOI: http://dx.doi. org/10.1177/0038038512448561.

Lora-Tamayo, G. (1993). Inmigrantes extranjeros y vivienda marginal en Madrid. Espacio, Tiempo y Forma. Geografia, 6, 153-168.

Manzano-Arrondo, V. y Suárez, E. (2015). Unidad de Acción Comprometida: una propuesta de solución ante el problema universitario del servicio a la sociedad. Hábitat y Sociedad, 8, 147-166.

Manzano-Arrondo, V. (2012). La Universidad Comprometida. Vitoria: Hegoa.

Méndez, M. (2009). ¿Sociedades de conocimientos o culturas del saber? Teoría y Praxis, 14, 49-63.

Menor, J. (2011). La movilidad de los inmigrantes temporeros para las campañas agrícolas: el caso de los marroquíes durante la recogida de la aceituna en la provincia de Jaén. En García, F.J. y Kressova, N. (eds.), Actas del I Congreso Internacional sobre Migraciones en Andalucía. Granada: Instituto de Migraciones, pp. 543-558.

Montero, M. (2005). Para una ética de la liberación: la liberación del otro en la psicología. En Portillo, M. Gaborit, y Cruz, J.M. (eds.), Psicología social en la posguerra: teoría y aplicaciones desde El Salvador. San Salvador: UCA Ediciones, pp. 410-435.

Morin, E. (1995). Introducción al pensamiento complejo. Barcelona: Gedisa.

- (2001). Los siete saberes necesarios para la educación del futuro. Barcelona: Paidós.

Paloma, V. y Manzano-Arrondo, V. (2011). The role of organizations in liberation psychology: applications to the study of migrations. Psychosocial Intervention, 20 (3), 309-318. DOI: http://dx.doi.org/10.5093/ in2011v20n3a7.

Pryor, R. y Bright, J. (2004). 'I had seen order and chaos, but had thought they were different.' The challenges of the chaos theory for career development. Australian Journal of Career Development, 13 (3), 18-22. DOI: http://dx.doi. org/10.1177/103841620401300305.

Ruiz, N. (2012). La definición y medición de la vulnerabilidad social. Un enfoque normativo. Investigaciones Geográficas, 77, 63-74. 
Saavedra, J. (2007). Adquirir la identidad en una comunidad de objetos: la identidad social dentro de la sociedad de consumo. Nómadas. Revista crítica de Ciencias Sociales y Jurídicas, 16, 1-18.

Sánchez, M.R. y Tezanos, S. (2004). Los inmigrantes "sin hogar" en España: un caso extremo de exclusión social. Revista del Ministerio de Trabajo y Asuntos Sociales, 55, 45-64.

Soto, J.L. (2007). El fenómeno migratorio desde la óptica de una nueva sensibilidad. Proyección: Teología y mundo actual, 226, 189-205.

Speck, B.W. (2001). Why Service-Learning? New Directions for Higher Education, 114, 3-13. DOI: http:// dx.doi.org/10.1002/he.8.abs.
Torres, F.J. (2011). El territorio de los desheredados. Asentamientos chabolistas y experiencias recientes de erradicación en Sevilla. Hábitat y Sociedad, 3, 6790 .

Vilar, S. (1997). La nueva racionalidad. Comprender la complejidad con métodos transdisciplinarios. Barcelona: Kairos.

Villagrán de León, J.C. (2006). Vulnerability. A conceptual and methodological review. Bonn: SOURCE UNU-EHS.

Wagensberg, J. (1985). Ideas sobre la complejidad del mundo. Barcelona: Tusquets Editores.

Wodak, R. (2003). El enfoque histórico del discurso. En Wodak, R. y Meyer, M. (eds.), Métodos de análisis crítico del discurso. Barcelona: Gedisa, pp. 101-142.

\section{Agradecimientos}

La parte metodológica de esta UAC habría sido inviable sin la participación emotiva, efectiva y de calidad profesional de las estudiantes que mencionamos a continuación. Su implicación se gesta en el seno de la asignatura "Metodología cualitativa", optativa de cuarto curso del grado de psicología en la Universidad de Sevilla: Alba León García, Eva Gasol Cerdiana, M. ${ }^{a}$ Cristina Lara García, M. ${ }^{a}$ del Mar Mejías Neira, María del Rocío Álvarez Morales, Marta Brosed Galán, Marta Pérez González, Raquel Torvisco Rebollo, Victoria Ramírez Barcia.

Manzano-Arrondo, V., Pedrosa, B. y Soto Soto, J. L. (2017). Sinhogarismo inmigante. Un caso de investigación-acción universitaria en el contexto de la recogida de la aceituna en Úbeda. $H a^{-}$ bitat y Sociedad, 10, 223-244.

<http:/ /dx.doi.org/10.12795/HabitatySociedad.2017.i10.13>

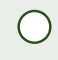

